Published in final edited form as:

Psychiatr Q. 2016 December ; 87(4): 675-688. doi:10.1007/s11126-016-9418-2.

\title{
Effects of Nativity, Length of Residence, and County-Level Foreign-Born Density on Mental Health Among Older Adults in the U.S
}

\author{
Sunha Choi ${ }^{1}$, Giyeon $\mathrm{Kim}^{2}$, and Sungkyu Lee ${ }^{3}$ \\ Sungkyu Lee: slee90@utk.edu \\ ${ }^{1}$ College of Social Work, The University of Tennessee, Knoxville, TN, USA \\ ${ }^{2}$ Alabama Research Institute on Aging and Department of Psychology, The University of \\ Alabama, Tuscaloosa, AL, USA \\ ${ }^{3}$ School of Social Welfare, Soongsil University, 369 Sangdo-Ro, Dongjak-Gu, Seoul 06978, Korea
}

\section{Abstract}

Using the 2004-2007 Medical Expenditure Panel Survey data that are linked to county-level data from the Area Health Resources Files, this study examined whether the healthy immigrant effect applies to mental health of foreign-born older adults. Additionally, testing a protective ethnic density effect on older foreign-born individuals' mental health, this study examined how the percentage of foreign-born population in the county affected the relationship between older adults' immigration status (U.S.-nativity and length of residence in the U.S.) and their mental health status. The sample included 29,011 individuals (level-1) from 920 counties (level-2) across 50 states and D.C. Using the Mental Component Summary of the Short-Form 12, the Kessler Index (K-6), and the Patient Health Questionnaire (PHQ-2), U.S.-born individuals $(\mathrm{n}=24,225)$, earlier immigrants ( $\geq 15$ years in the U.S.; $\mathrm{n}=3866$ ), and recent immigrants $(<15$ years in the U.S.; $\mathrm{n}=$ 920) were compared. The results indicate that recent immigrants showed worse mental health on all three measures compared with U.S.-born individuals and on the K-6 and PHQ-2 compared with earlier immigrants. Higher county-level foreign-born densities were associated with worse mental health status of individuals. However, the significant interactions found in the full conditional multilevel models indicated that the high foreign-born density functioned as a risk factor for worse mental health only among recent immigrants but not among the U.S.-born. In conclusion, the results revealed the vulnerability of older recent immigrants, especially those living in the counties with high foreign-born densities.

Correspondence to: Sungkyu Lee, slee90@utk . edu.

Conflict of interest All authors declare that we have no conflict of interest.

Ethical approval All procedures performed in studies involving human participants were in accordance with the ethical standards of the institutional and/or national research committee and with the 1964 Helsinki declaration and its later amendments or comparable ethical standards.

Human and animal rights statement This article does not contain any studies with human participants performed by any of the authors. This study used a publicly available secondary database, which does not contain any identifying information.

Informed consent Informed consent is not applicable. 


\section{Keywords}

Depression; Psychological distress; Health immigrant effect; Ethnic density effect

\section{Introduction}

The healthy immigrant effect (HIE) suggests that upon immigration, foreign-born individuals are healthier than their native-born counterparts because of the self-selection of healthy individuals into international immigration [1-3]. However, among older adults, the HIE is only partially supported [4]. This is most likely due to the different motivations for migration between younger and late-in-life immigrants. While healthy younger immigrants tend to migrate for job opportunities (i.e., employment-based immigration), older adults are likely to migrate to reunite with their immigrant children or relatives who have settled in the U.S. (i.e., family-based immigration) [5].

Beyond physical health, however, it is not known whether the notion of the HIE can be extended to relative mental health status of older foreign-born individuals compared with their native-born counterparts. The alternative theoretical framework to understand mental health status of foreign-born individuals would be the stress-illness model, which hypothesizes that upon immigration, mental health of foreign-born individuals is worse than that of native-born individuals due to the difficulties associated with acculturation in a new country [6].

With regard to physical health and the HIE, the initial health advantages among new immigrants tend to disappear over time as the immigrants' lifestyles become similar to those of their native-born counterparts as a result of acculturation and as they begin to share the same physical and social environments in a host country. Similarly, the stress-illness model hypothesizes that the health or mental health of foreign-born individuals would improve over time and become similar to the mental health status of native-born individuals as the foreignborn individual's level of acculturation increases over time in the host country. Previous studies have found a positive relationship between length of residence in a host country and the level of acculturation among younger foreign-born individuals [7-9]. Thus, it is hypothesized that longer-term immigrants would represent better mental health status than new immigrants because of their reduced acculturative stress over time. However, older adults are known to be less adaptable to the new culture and language of a host country compared with their younger immigrant counterparts [10]. Thus, it is less known how the length of residence in the U.S. is associated with mental health status among older foreignborn individuals.

In addition, little is known about how older foreign-born individuals' mental health status is affected by contextual factors that are associated with where they live. Previous literature has demonstrated a strong association between contextual environments and an individual's health and health behaviors [11-15]. According to the ecological and systematic perspective, individuals' behaviors are affected by and interact with higher level social systems, including communities, organizations, and social policies [16]. The members of a community share the same physical and social environment, and by doing so, they are likely 
to share the same risk or protective factors that are associated with their health status (e.g., population density, lack of job opportunities and resources in the community) [17].

Particularly related to foreign-born individuals, previous studies examined how foreign-born ethnic densities in the areas affected foreign-born individuals' health and mental health. The high proportion of ethnic minority residents in an area may play a protective role (i.e., the ethnic density effect) on minority individuals' mental health because a high ethnic density provides greater opportunities to utilize social networks and culturally sensitive services, and lowers perceived racism and discrimination among minority individuals including immigrants $[18,19]$. However, a high ethnic density is also associated with adverse characteristics, such as deprivation of resources and lower perceived safety [20], which, in turn, are associated with worse mental health status of residents. Accordingly, previous studies reported mixed findings in terms of the role of ethnic density on health and health behaviors: while some studies found protective effects, adverse or no effects were found in other studies [21].

Considering these mixed findings in the literature, we examined how the percentage of foreign-born individuals in the county affects mental health of older foreign-born individuals. Given the importance of immigrant enclaves, which facilitate acculturation process of newly-arrived foreign-born individuals [22], we hypothesized a protective effect of foreign-born population density on mental health especially among older foreign-born individuals with shorter length of residence in the U.S., while aiming to extend the HIE to mental health of older adults.

Thus, this study addresses the following research questions:

1. To what extent does mental health status differ by nativity and length of residence in the U.S. among individuals aged 50 or older after controlling for individual- and county-level covariates?

2. To what extent does the county-level foreign-born population density moderate the relationship between mental health status and nativity and length of residence in the U.S. among individuals aged 50 or older?

\section{Methods}

\section{Data}

This study used individual-level data nested in their counties. For the individual-level data, we analyzed the 2004-2007 Medical Expenditure Panel Survey (MEPS). The MEPS is a nationally representative survey of the U.S. civilian non-institutionalized population's healthcare utilization [23]. To acquire participants' foreign-born status and length of residence in the U.S., the MEPS data were linked to the National Health Interview Survey (NHIS) by common individual identification number because each year's sample for the MEPS is drawn from the NHIS.

Respondents' county characteristics were obtained from the Area Health Resources Files (AHRF) and merged with the individual-level data by common county identifier. Distributed 
by the Health Resources and Services Administration of the U.S. Department of Health and Human Services, the 2009 AHRF contains the historic, multi-year estimates of healthcare resources and socioeconomic characteristics of a given geographic area through 2007 and incorporates community-level data from different sources including the 2000 U.S. Census and the 2004 Census County Characteristics File (http://ahrf.hrsa.gov/).

To protect the respondents' confidentiality, geographic identifiers are not available in the public MEPS and NHIS data. To gain access to the restricted information, the data analysis procedures followed the guidelines established for using the restricted data collected by the Agency for Healthcare Research and Quality (AHRQ). This study was approved by the University Institutional Review Board.

\section{Sample}

The MEPS used a stratified multi-stage area probability sampling method with counties stratified by state as a primary sampling unit [24]. The sample consisted of 29,011 individuals aged 50 or older at the time of their interview (level-1 sample size) from 920 counties (level-2 sample size) across 50 states and Washington D.C. in the U.S. The sample was divided into three groups by immigrant status: (a) 24,225 U.S.-born, (b) 3866 foreignborn individuals who had lived in the U.S. for 15 years or longer (earlier immigrants; nested in 308 counties across 48 states), and (c) 920 foreign-born individuals with less than 15 years of residence in the U.S. (recent immigrants; nested in 158 counties across 38 states).

\section{Measures}

Mental Health Status-Three standardized measures were used in this study: the Mental Component Summary (MCS) of the Short-Form 12 (SF-12), the Kessler Index (K-6), and the Patient Health Questionnaire (PHQ-2). The three measures capture different aspects of mental health status and have been widely used and tested with older adults [25, 26]. The MCS of the SF-12 assesses the general self-rated psychological symptoms (e.g., felt downhearted, accomplished less due to mental problems) and limitations in daily activities due to mental health problems over the past 4 weeks [27]. The score ranges from 0 to 100 , with higher scores indicating better mental health status. The K-6 assesses non-specific psychological distress [28] using six items. The questions include, for example, how often a respondent felt nervous, hopeless, or worthless during the past 30 days on a scale of 0 ("none of the time") to 4 ("all of the time"). The higher total scores indicate greater tendencies towards mental disability, and a score of 13 has been used to screen for serious psychological distress [29]. The PHQ-2 consists of two items that can be used as a quick screener for depression in the primary care setting [30]. The two questions assess how often during the past 2 weeks the respondent was bothered by (a) having little interest or pleasure in doing things and (b) feeling down, depressed, or hopeless. Each question was answered on a scale of 0 ("not at all") to 3 ("nearly every day"). Previous studies suggest a score of three or greater as the cut-off score for depression [31, 32].

Individual-Level Covariates-Demographic variables included age (in years), female (=yes/no), education (years completed), individual income (in 2007 dollars), and marital status (=currently married, not married, never married). Respondents were divided into four 
groups based on their ethnicity (Hispanic $=$ yes $/$ no $)$ and race $(=$ White, Black, and Other): Non-Hispanic White, Hispanic White, Black, and Other. Because only 39 out of 3994 Black respondents $(1 \%)$ were Hispanic, this group was not divided by their Hispanic ethnicity. To reflect health status, the number of lifetime diagnoses of the following ten chronic health conditions were counted: diabetes, asthma, blood pressure, coronary heart disease, angina, heart attack, other heart disease, stroke, emphysema, and arthritis. Additionally, a dichotomous variable (=yes/no) was created to assess if a respondent had limitations in activities of daily living (ADL), instrumental activities of daily living (IADL), any physical activities, or sensory (hearing or vision) functions.

County-Level Covariates-The county-level factors that were known to be associated with individuals' mental health were selected based on a review of previous empirical studies [14, 33-35]. The county-level socioeconomic and compositional characteristics included in the analysis are the population densities (\%) of foreign-born individuals, uninsured individuals below age 65 , unemployed individuals, and individuals in poverty in the counties where respondents resided. In addition, the number of people per square mile and the percentage of female-headed households were also tested as county-level covariates.

\section{Data Analysis}

Descriptive and bivariate statistics were used to compare individual- and county-level characteristics by nativity and the length of residence in the U.S. (i.e., immigrant status) using STATA's survey procedures to reflect the complex sampling design of the pooled MEPS data [36]. Multilevel models were conducted using STATA XTMIXED to test whether immigrant status was significantly related to mental health status after controlling for the effects of geographic clustering and the effects of other selected individual-level and county-level covariates [37]. Interactions between immigrant status (reference: recent immigrants) and the percentage of foreign-born individuals in the county (continuous variable) were tested in the final models.

\section{Results}

\section{Descriptive Characteristics by Nativity and Length of Residence in the U.S}

As presented in Table 1, recent immigrants and U.S.-born individuals were significantly different in terms of their individual-level and county-level characteristics. Compared with U.S.-born individuals, recent immigrants were more likely to be younger, less educated, of lower income, and currently married. The recent immigrant group included a higher proportion of Hispanic White (36.6\%) and Other (34.7\%) compared with the U.S.-born (3.0\% and $2.5 \%$, respectively). Recent immigrants showed better health status in that they were less likely to have any physical, sensory, or functional limitations $(31.3 \%)$ and had fewer chronic health conditions (mean $=1.08)$ compared with U.S.-born individuals $(46.7 \%$ and mean $=1.63$, respectively). In addition, recent immigrants lived in counties with more disadvantageous characteristics: higher percentages of the foreign-born, uninsured, people in poverty and families with female heads. Recent immigrants were also more likely to live in counties with high population density per square mile. 
The two foreign-born groups were similar to each other in terms of the county-level characteristics of where they resided. However, as seen in Table 1, earlier immigrants were significantly different from recent immigrants in terms of age, education, income, race/ ethnicity, and health. The earlier immigrant group stood in the middle between the recent immigrant and the U.S.-born groups in those characteristics. For example, although the mean years of education for earlier immigrants (11.5 years) was greater than that of recent immigrants (10.6 years), it was lower than that of the U.S.-born (13.1 years).

\section{Bivariate Comparison}

Recent immigrants showed the worst mental health statuses on the three measures (Table 2). The overall psychological distress level, measure by K6, for recent immigrants was significantly higher than that of earlier immigrants $(\mathrm{p}<.05)$ and U.S.-born individuals $(\mathrm{p}<$. $01)$. In addition, a higher percentage of recent immigrants had a score that was equal to or greater than the cut off score for serious psychological distress (10\%) compared with earlier immigrants $(7.2 \%, \mathrm{p}<.05)$ and the U.S.-born $(5.4 \%, \mathrm{p}<.001)$. Regarding depression status, measured by PHQ-2, the recent immigrant group had the highest mean score (1.14) compared with earlier immigrants $(0.91, \mathrm{p}<.05)$ and the U.S.-born $(0.76, \mathrm{p}<.001)$. Although $16 \%$ of recent immigrants scored three or higher on PHQ-2 (i.e., cut off to screen for depression), it was $12.7 \%$ among earlier immigrants ( $\mathrm{p}<.05)$ and $9.6 \%$ among U.S.born older adults $(\mathrm{p}<.001)$. For the SF-12's MCS, the difference was found only between recent immigrants and U.S.-born older adults with recent immigrants having worse mental health status $(\mathrm{p}<.01)$.

\section{Conditional Multilevel Models}

When tested in the conditional multilevel models without interaction terms between immigrant status and the foreign-born population density of the county (Model As in Table 3 ), the results indicated that recent immigrants had the highest score on the K6 (i.e., highest psychological distress) compared with earlier immigrants $(b=-0.45, \mathrm{p}<.01)$ and the U.S.born $(b=-0.58, \mathrm{p}<.01)$.

When the interaction terms were introduced to examine how the relationship between immigrant and mental health statuses differ by the foreign-born density of the county (Model Bs in Table 3), the results indicate the significant interaction effects $(\mathrm{p}<.05)$ in the models for the MCS and PHQ-2. As seen in Table 4, increases in the foreign-born density at the county level were associated with worse mental health statuses across three groups and three measures in terms of the directions of the coefficients. However, the adverse effects of the county-level foreign-born density on individuals' mental health were close to zero among the U.S.-born (e.g., $b=0.002$ for the PHQ-2 among the U.S.-born), while the adverse effects were greater among recent immigrants (e.g., $b=0.02$ for the PHQ-2 among recent immigrants) when the same models were run by each group. As seen in Model Bs for the PHQ-2 and MCS in Table 3, the differences between U.S.-born and recent immigrant individuals would be greater only among those individuals who live in the counties with high foreign-born densities. 


\section{Discussion}

This study sought to examine how immigrant status (i.e., recent immigrants, earlier immigrants, and U.S.-born individuals) is associated with mental health status among older adults. It also investigated how county-level foreign-born population density moderated the relationship between immigrant and mental health status. We found clear evidence that older recent immigrants, in general, had poorer mental health than their U.S.-born counterparts.

The most intriguing finding was the vulnerability of older recent immigrants residing in immigrant enclaves to their mental health. The significant moderating effects revealed that older recent immigrants who live in the counties with high foreign-born population densities were most vulnerable to worse mental health symptoms compared with their recent immigrant counterparts who live in counties with low concentration of foreign-born individuals or their U.S.-born counterparts. This is contradictory to the previously reported protective mechanism associated with residing in immigrant enclaves [38, 39]. Although reasons for the negative effect of immigrant enclaves on immigrants' mental health are not well known in the literature, there may be several potential reasons that could elucidate our contradictory findings in this study. First, our study focuses on mental health outcomes, whereas other studies reporting the protective effect focus on physical health outcomes [e.g., 22]. Previous research reported that patterns of physical and mental health status of individuals could differ drastically within the same racial/ethnic group [40]. Second, our study focuses on older adults, whereas many other studies reporting the protective effect of immigrant enclave residence were conducted among younger adult samples [22]. Younger and older immigrants may experience different levels of acculturative stress after immigration [7], which may be linked to different mental health outcomes between younger and older adults. It is also possible that foreign-born individuals with lower levels of acculturation, such as those with limited English proficiency, are more likely to remain in the ethnic enclaves or in the areas with high foreign-born densities [41]. Thus, the significant effects of the county-level foreign-born population density on mental health may be due to the compositional effects of the residents who live in those counties. Despite the reported collective benefits of immigrant enclaves such as psychosocial support, resource sharing, and shared information on available health care services [39], further examination should be required to understand the specific mechanism of how immigrant enclaves affect the mental health of recently immigrated elders using a multilevel approach.

It should be highlighted that contrary to the well-known HIE [1-3], recent immigrants in our study showed poorer mental health status compared with earlier immigrants and U.S.-born individuals. It is worth noting, however, that older recent immigrants had better physical health conditions than earlier immigrants or U.S.-born individuals in our study, which is in concordance with the HIE. Although we were unable to directly test the relation in our study, older recent immigrants' poorer mental health compared with earlier immigrants may be related to greater acculturative stress among new immigrants as suggested in the stressillness model, which may be developed during the process of adjusting to the new host culture after immigration. Previous research discussed an important role of acculturative stress in immigrants' poor mental health [42], and this question should be further investigated in future research as an extension from this study. 
Our findings have clinical and policy implications. Healthcare professionals serving older immigrants should recognize the potential risks for poor mental health among older recent immigrants, especially those residing in immigrant enclaves. Future interventions might need to focus on areas with high foreign-born densities to improve mental health among recently arrived older foreign-born individuals. Additionally, mental health programs and policies should target the areas with high foreign-born densities to improve older immigrants' mental health.

Some study limitations should be discussed. First, although we did not compare immigrant groups by race/ethnicity, subgroup differences within the same racial/ethnic group may exist in terms of the relation between nativity and county-level characteristics and should be explored further. Second, immigration-related factors such as age at immigration, the level of acculturation, and acculturative stress were not available in the MEPS or NHIS data, which may be worth examining in future research to explain differences between recent and earlier immigrants. In addition, although we found that longer lengths of stay were associated with better mental health status by comparing recent and earlier immigrants, further studies should use longitudinal data to track changes over time. Lastly, the comparability of the three outcome measures (i.e., K6, MSC, and PHQ-2) should be further investigated, to explain the inconsistent findings of interaction effects of immigration status and foreign-born density. Relatedly, measurement equivalence of the three measures has not been tested in this study. Given that recent studies reported the possibility of measurement nonequivalence in the K6 across diverse groups [40, 43], results relating to the K6 should be interpreted with caution.

Despite these limitations, findings from our multilevel analytic approach provided clear evidence that residing in an immigrant enclave is associated with worse mental health status among older recent immigrants. This study highlights the importance of understanding older immigrants' mental health within the environmental context. Overall, this study contributes to the literature by employing multilevel modeling approach and by examining the moderating effects of community-level factors on older immigrants' mental health status. Findings inform future interventions for immigrants with poor mental health status in terms of the specific type of group and their geographic locations in order to improve immigrant elders' mental health and their overall well-being.

\section{Acknowledgments}

This study was funded by the Silberman Fund Faculty Grant Program (PI: S. Choi) and the National Institute on Aging (K01AG045342; PI: G. Kim). The data analysis in this paper was conducted at the Atlanta Research Data Center, and the support of the Agency for Healthcare Research and Quality (AHRQ) is acknowledged. The content is solely the responsibility of the authors and does not necessarily represent the official views of the National Institute on Aging or AHRQ.

\section{Biographies}

Sunha Choi, PhD is an Assistant Professor with College of Social Work at the University of Tennessee, Knoxville. Dr. Choi is a Visiting Scholar at the Atlanta Census Research Data Center and her recent funded projects focus on examining how individuals' health and 
service use behaviors are affected by the community's contextual characteristics. In 2011, Dr. Choi was selected as Hartford Geriatric Social Work Faculty Scholars (Cohort 10).

Giyeon Kim, PhD is an Associate Professor in the Alabama Research Institute on Aging and the Department of Psychology at The University of Alabama. She is a gerontologist who studies aging and mental health disparities. Her research focuses primarily on racial and ethnic disparities in mental health and mental health care among older adults.

Sungkyu Lee, $\mathbf{P h D}$ is an Assistant Professor at Soongsil University School of Social Welfare. His areas of research interests include mental health services for people with severe mental illness and disparities in access to health care services among vulnerable populations, including immigrants.

\section{References}

1. Antecol H, Bedard K. Unhealthy assimilation: Why do immigrants converge to American health status levels? Demography. 2006; 43(2):337-360. [PubMed: 16889132]

2. McDonald JT, Kennedy S. Insights into the 'healthy immigrant effect': Health status and health service use of immigrants to Canada. Social Science \& Medicine. 2004; 59:1613-1627. [PubMed: 15279920]

3. Akresh IR, Frank R. Health selection among new immigrants. American Journal of Public Health. 2008; 98(11):2058-2064. DOI: 10.2105/ajph.2006.100974 [PubMed: 18309141]

4. Choi S. Testing healthy immigrant effects among late life immigrants in the United States: Using multiple indicators. Journal of Aging and Health. 2012; 24(3):475-506. DOI: 10.1177/0898264311425596 [PubMed: 22108546]

5. Treas J, Mazumdar S. Older people in America's immigrant families dilemma of dependence, integration, and isolation. Journal of Aging Studies. 2002; 16:243-258.

6. Friis R, Yngve A, Persson V. Review of social epidemiologic research on migrants' health: Findings, methodological cautions, and theoretical perspectives. Scandinavian Journal of Social Medicine. 1998; 26(3):173-180. [PubMed: 9768446]

7. Wilton L, Constantine MG. Length of residence, cultural adjustment difficulties and psychological distress symptoms in Asian and Latin American international college students. Journal of College Counseling. 2003; 6:177-186.

8. Ayoob M, Singh T, Jan M. Length of stay, acculturative stress, and health among Kashmiri students in Central India. Pakistan Journal of Social \& Clinical Psychology. 2011; 9(1):11-15.

9. Miglietta A, Tartaglia S. The influence of length of stay, linguistic competence, and media exposure in immigrants' adaptation. Cross-Cultural Research. 2009; 43:46-61.

10. Diwan S, Jonnalagadda SS, Balaswamy S. Resources predicting positive and negative affect during the experience of stress: A study of older Asian Indian immigrants in the United States. Gerontologist. 2004; 44(5):605-614. [PubMed: 15498836]

11. Andersen RM, Yu H, Wyn R, Davidson PL, Brown ER, Teleki S. Access to medical care for lowincome persons: How do communities make a difference? Medical Care Research and Review. 2002; 59(4):384-411. [PubMed: 12508702]

12. Mathur C, Erickson DJ, Stigler MH, Forster JL, Finnegan JR. Individual and neighborhood socioeconomic status effects on adolescent smoking: A multilevel cohort-sequential latent growth analysis. American Journal of Public Health. 2013; 103(3):543-548. DOI: 10.2105/ajph. 2012.300830 [PubMed: 23327273]

13. Kirby JB, Kaneda T. Neighborhood socioeconomic disadvantage and access to health care. Journal of Health and Social Behavior. 2005; 46:15-31. [PubMed: 15869118]

14. Aneshensel GS, Wight RG, Miller-Martinez D, Botticello AL, Karlamangla AS, Seeman TE. Urban neighborhoods and depressive symptoms among older adults. Journal of Gerontology: Social Sciences. 2007; 62B(1):S52-S59. 
15. Grafova IB, Freedman VA, Kumar R, Rogowski J. Neighborhoods and obesity in later life. American Journal of Public Health. 2008; 98(11):2065-2071. DOI: 10.2105/AJPH.2007.127712 [PubMed: 18799770]

16. Zastrow, C.; Kirst-Ashman, KK. Understanding human behavior and the social environment. Belmont: Brooks/Cole; 2013.

17. Fitzpatrick KM, LaGory M. "Placing" health in an urban sociology: Cities as mosaics of risk and protection. City \& Community. 2003; 2(1):33-46. DOI: 10.1111/1540-6040.00037

18. Whitley R, Prince M, McKenzie K, Stewart R. Exploring the ethnic density effect: A qualitative study of a London electoral ward. International Journal of Social Psychiatry. 2006; 52(4):376-391. DOI: 10.1177/0020764006067239 [PubMed: 17262983]

19. Lee M, Liechty J. Longitudinal associations between immigrant ethnic density, neighborhood processes, and latino immigrant youth depression. Journal of Immigrant and Minority Health. 2015; 17(4):983-991. DOI: 10.1007/s10903-014-0029-4 [PubMed: 24801717]

20. Osypuk TL, Diez Roux AV, Hadley C, Kandula NR. Are immigrant enclaves healthy places to live? The Multi-ethnic Study of Atherosclerosis. Social Science \& Medicine. 2009; 69(1):110-120. DOI: 10.1016/j.socscimed.2009.04.010 [PubMed: 19427731]

21. Bécares L, Shaw R, Nazroo J, Stafford M, Albor C, Atkin K, et al. Ethnic density effects on physical morbidity, mortality, and health behaviors: A systematic review of the literature. American Journal of Public Health. 2012; 102(12):e33-e66. DOI: 10.2105/AJPH.2012.300832 [PubMed: 23078507]

22. Stafford M, Becares L. Findings from a United Kingdom General Population Survey. American Journal of Epidemiology. 2009; 170(4):484-493. DOI: 10.1093/aje/kwp160 [PubMed: 19608764]

23. Agency for Healthcare Research Quality (AHRQ). MEPS HC-105: 2006 full-year consolidated data file. Rockville, MD: Author; 2008.

24. Agency for Healthcare Research Quality (AHRQ). Methodology report \#22: Sample design of the Medical Expenditure Panel Survey household component, 1998-2007. Rockville, MD: Author; 2008.

25. Li F, Bruce F, Yeates Conwell, Kevin Fiscella. Validity of the Patient Health Questionnaire 2 (PHQ-2) in identifying major depression in older people. Journal of American Geriatrics Society. 2007; 55(4):596-602.

26. McManus DP, Sharon S, Whooley Mary A. Screening for depression in patients with coronary heart disease: Data from the Heart and Soul Study. The American Journal of Cardiology. 2005; 96(8):1076-1081. [PubMed: 16214441]

27. Ware, JE.; Kosinski, M.; Turner-Bowler, DM.; Gandek, B. How to score version 2 of the SF-12 health survey. Lincoln, R.I: QualityMetric Inc; 2002.

28. Kessler RC, Andrews G, Colpe LJ, Hiripi E, Mroczek DK, Normand SLT, et al. Short screening scales to monitor population prevalences and trends in non-specific psychological distress. Psychological Medicine. 2002; 32(06):959-976. DOI: 10.1017/S0033291702006074 [PubMed: 12214795]

29. Prochaska JJ, Sung H-Y, Max W, Shi Y, Ong M. Validity study of the K6 scale as a measure of moderate mental distress based on mental health treatment need and utilization. International Journal of Methods in Psychiatric Research. 2012; 21(2):88-97. DOI: 10.1002/mpr.1349 [PubMed: 22351472]

30. Arroll B, Goodyear-Smith F, Crengle S, Gunn J, Kerse N, Fishman T, et al. Validation of PHQ-2 and PHQ-9 to screen for major depression in the primary care population. The Annals of Family Medicine. 2010; 8(4):348-353. DOI: 10.1370/afm.1139 [PubMed: 20644190]

31. Unutzer J, Schoenbaum M, Katon WJ, Fan MY, Pincus HA, Hogan D, et al. Healthcare costs associated with depression in medically Ill fee-for-service medicare participants. Journal of American Geriatrics Society. 2009; 57(3):506-510. DOI: 10.1111/j.1532-5415.2008.02134.x

32. Kroenke K, Spitzer RL, Williams JB. The Patient Health Questionnaire-2: Validity of a two-item depression screener. Medical Care. 2003; 41(11):1284-1292. DOI: 10.1097/01.mlr. 0000093487.78664.3c [PubMed: 14583691] 
33. Beard JR, Cerdá M, Blaney S, Ahern J, Vlahov D, Galea S. Neighborhood characteristics and change in depressive symptoms among older residents of New York City. American Journal of Public Health. 2009; 99(7):1308-1314. [PubMed: 19008519]

34. Kubzansky LD, Subramanian SV, Kawachi I, Fay ME, Soobader M-J, Berkman LF. Neighborhood contextual influences on depressive symptoms in the elderly. American Journal of Epidemiology. 2005; 162(3):253-260. DOI: 10.1093/aje/kwi185 [PubMed: 15987730]

35. Santiago CD, Wadsworth ME, Stump J. Socioeconomic status, neighborhood disadvantage, and poverty-related stress: Prospective effects on psychological syndromes among diverse low-income families. Journal of Economic Psychology. 2011; 32(2):218-230. DOI: 10.1016/j.joep. 2009.10.008

36. Stata Press. STATA reference manual: Survey data. College Station: Stata Press; 2007.

37. Rabe-Hesketh, S.; Skrondal, A. Multilevel and longitudinal modeling using Stata: Continuous responses. College Station: Stata Press; 2012.

38. Kim YA, Collins TW, Grineski SE. Neighborhood context and the Hispanic health paradox: Differential effects of immigrant density on childrens wheezing by poverty, nativity and medical history. Health Place. 2014; 27:1-8. DOI: 10.1016/j.healthplace.2014.01.006 [PubMed: 24509419]

39. Cagney KA, Browning CR, Wallace DM. The Latino paradox in neighborhood context: The case of asthma and other respiratory conditions. American Journal of Public Health. 2007; 97(5):919925. [PubMed: 17395846]

40. Kim G, Bryant AN, Parmelee P. Racial/ethnic differences in serious psychological distress among older adults in California. International Journal of Geriatric Psychiatry. 2012; 27:1070-1077. DOI: 10.1002/gps.2825 [PubMed: 22161758]

41. Kritz MM, Gurak DT, Lee M-A. Foreign-born out-migration from new destinations: Onward or back to the enclave? Social Science Research. 2013; 42(2):527-546. DOI: 10.1016/j.ssresearch. 2012.09.013 [PubMed: 23347493]

42. Jang Y, Chiriboga DA. Living in a different world: Acculturative stress among Korean American elders. The Journals of Gerontology B: Psychological Sciences and Social Sciences. 2010; 65:1421. [PubMed: 19346438]

43. Andersen LS, Grimsrud A, Myer L, Williams DR, Stein DJ, Seedat S. The psychometric properties of the K10 and K6 scales in screening for mood and anxiety disorders in the South African Stress and Health study. International Journal of Methods in Psychiatric Research. 2011; 20(4):215-223. DOI: 10.1002/mpr.351 [PubMed: 22113964] 
Table 1

Sample characteristics by nativity and length of residence in the U.S. (Ages 50+): Weighted mean or \% (95\% confidence interval) $(\mathrm{N}=29,011)$

\begin{tabular}{|c|c|c|c|}
\hline & $\begin{array}{l}\text { Recent immigrants } \\
(\text { Reference, } \mathrm{N}=920)^{a}\end{array}$ & $\begin{array}{l}\text { Earlier immigrants } \\
(\mathbf{N}=3866)\end{array}$ & $\begin{array}{l}\text { U.S.-born } \\
(\mathbf{N}=\mathbf{2 4 , 2 2 5})\end{array}$ \\
\hline \multicolumn{4}{|l|}{ Individual-level characteristics } \\
\hline Age (in years) & $59.4(58.3-60.4)$ & $63.2(62.6-63.8)^{* * *}$ & $63.5(63.3-63.8)^{* * * *}$ \\
\hline Age 50-64 (=yes, \%) & $76.1(70.8-80.7)$ & $61.5(58.7-64.2)^{* * *}$ & $59.7(58.5-60.9)^{* * * *}$ \\
\hline Female (=yes) & $58.0(53.7-62.2)$ & $53.9(51.9-55.9)$ & $53.8(53.2-54.5)$ \\
\hline Education (in years) & $10.6(9.9-11.3)$ & $11.5(11.2-11.8)^{*}$ & $13.1(13.0-13.2)^{* * *}$ \\
\hline Income (in 2007\$) & $22,645(19,161-26,129)$ & $32,068(30,011-34,126)^{* * *}$ & $36,327(35,408-37,246){ }^{* * * *}$ \\
\hline \multicolumn{4}{|l|}{ Race/Ethnicity } \\
\hline Non-Hispanic White & $22.3(16.2-29.8)$ & $30.9(27.8-34.1)^{*}$ & $85.3(84.2-86.4)^{* * * *}$ \\
\hline Hispanic White & $36.6(30.9-42.8)$ & $37.8(34.4-41.4)$ & $3.0(2.4-3.6)^{* * *}$ \\
\hline Black & $6.4(3.9-10.4)$ & $6.3(5.2-7.6)$ & $9.2(8.4-10.1)$ \\
\hline Other & $34.7(28.8-41.1)$ & $25.0(21.4-28.9)^{* *}$ & $2.5(2.1-3.1)^{* * *}$ \\
\hline \multicolumn{4}{|l|}{ Marital Status } \\
\hline Currently married & $67.3(62.4-71.9)$ & $63.9(61.1-66.6)$ & $61.7(60.5-63.0)^{*}$ \\
\hline Not married & $26.0(21.7-30.8)$ & $30.3(27.8-33.0)$ & $32.7(31.6-33.8)^{* *}$ \\
\hline Never married & $6.7(4.4-10.1)$ & $5.8(4.7-7.2)$ & $5.6(5.1-6.0)$ \\
\hline Any limitation (=yes) & $31.3(26.4-36.7)$ & $36.7(34.4-39.0)$ & $46.7(45.4-48.0)^{* * *}$ \\
\hline$\#$ of health conditions & $1.08(0.94-1.22)$ & $1.34(1.27-1.42)^{* *}$ & $1.63(1.60-1.67)^{\text {*** }}$ \\
\hline \multicolumn{4}{|l|}{ County-level characteristics } \\
\hline$\%$ foreign-born & $21.8(20.1-23.5)$ & $20.6(19.4-21.7)$ & $8.2(7.8-8.7)^{* * *}$ \\
\hline$\%$ uninsured (under 65) & $19.2(18.5-19.9)$ & $18.7(18.1-19.4)$ & $16.3(16.0-16.7)^{* * * *}$ \\
\hline$\%$ unemployed & $5.8(5.5-6.0)$ & $5.7(5.5-5.9)$ & $5.6(5.5-5.8)$ \\
\hline Population density (per square mile) & $5006(3149-6863)$ & $5100(4283-5919)$ & $1301(1173-1429)^{* * *}$ \\
\hline$\%$ in poverty & $13.6(12.8-14.3)$ & $13.2(12.7-13.8)$ & $12.6(12.3-12.9)^{* *}$ \\
\hline$\%$ families with female head & $20.0(19.1-20.9)$ & $19.6(19.1-20.1)$ & $17.4(17.0-17.7)^{* * *}$ \\
\hline \multicolumn{4}{|l|}{${ }^{*}<.05$} \\
\hline $\begin{array}{l}* * * 01, \\
* * * \\
* 0.001\end{array}$ & & & \\
\hline
\end{tabular}

Psychiatr Q. Author manuscript; available in PMC 2016 December 01. 


\section{Table 2}

Mental health status among adults aged 50 or older by length of residence and nativity: Weighted mean or \% (95\% confidence interval)

\begin{tabular}{llll}
\hline & ${\text { Recent immigrants }\left(\text { reference }^{a}\right)}$ Earlier immigrants & U.S.-born \\
\hline K6 & $4.67(4.03-5.32)$ & $3.90(3.64-4.15)^{*}$ & $3.50(3.40-3.59)^{* *}$ \\
K6 $\geq 13(\%)$ & $10.0(7.4-13.5)$ & $7.2(6.1-8.4)^{*}$ & $5.4(5.0-5.8)^{* * *}$ \\
PHQ-2 & $1.14(0.97-1.30)$ & $0.91(0.84-0.99)^{*}$ & $0.76(0.73-0.79)^{* * *}$ \\
PHQ-2 $\geq 3$ & $16(12.8-20.0)$ & $12.7(11.3-14.3)^{*}$ & $9.6(9.1-10.2)^{* * *}$ \\
MCS (SF12) & $49.55(48.37-50.73)$ & $50.73(50.22-51.24)$ & $51.67(51.46-51.88)^{* *}$ \\
\hline
\end{tabular}

* $<.05$,

***. $<1$,

$* * * .001$

a Bivariate statistical tests were conducted using Stata's SVY REG and SVY LOGISTIC depending on the characteristics of the variables, with recent immigrants as a reference group 


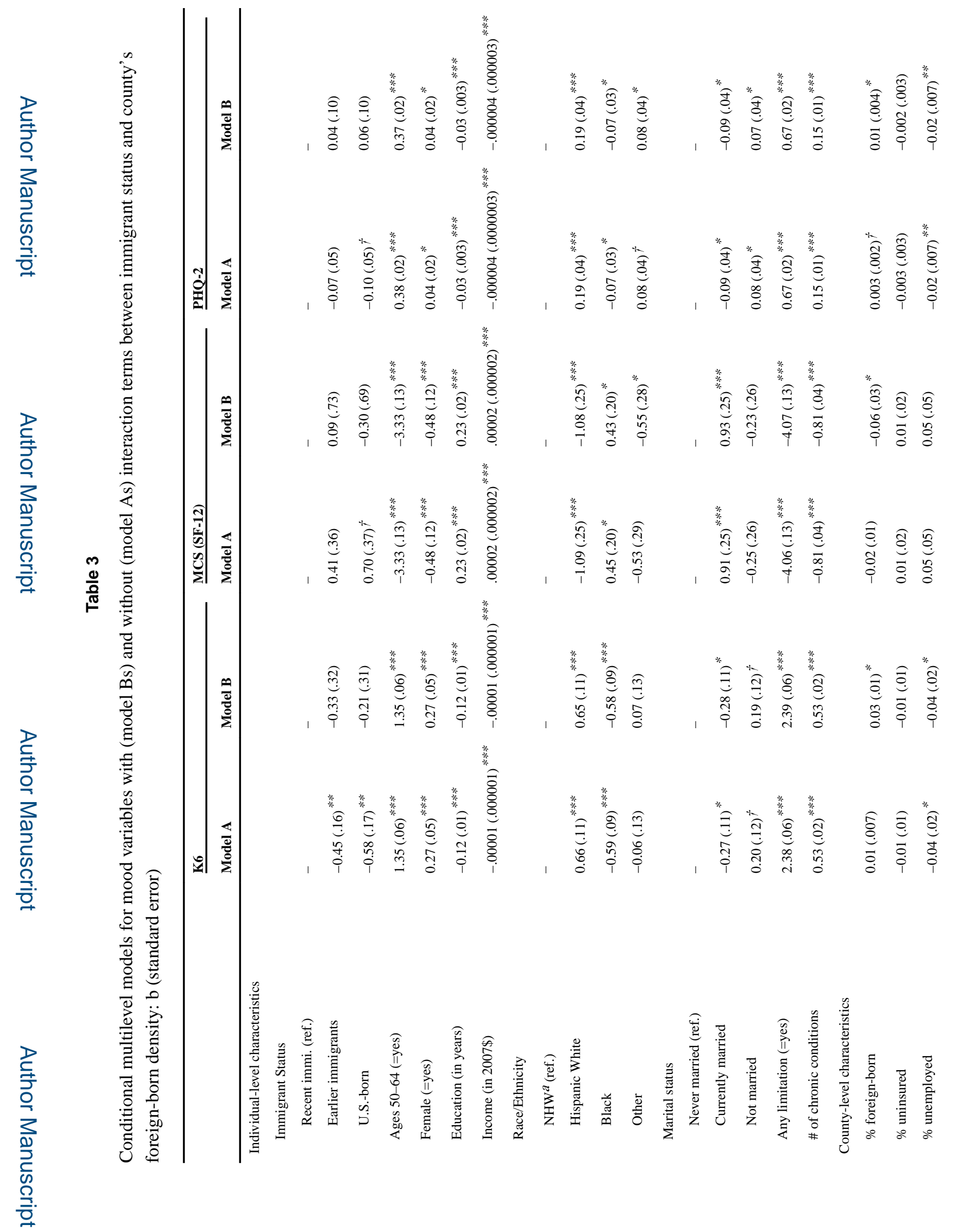

Psychiatr Q. Author manuscript; available in PMC 2016 December 01. 


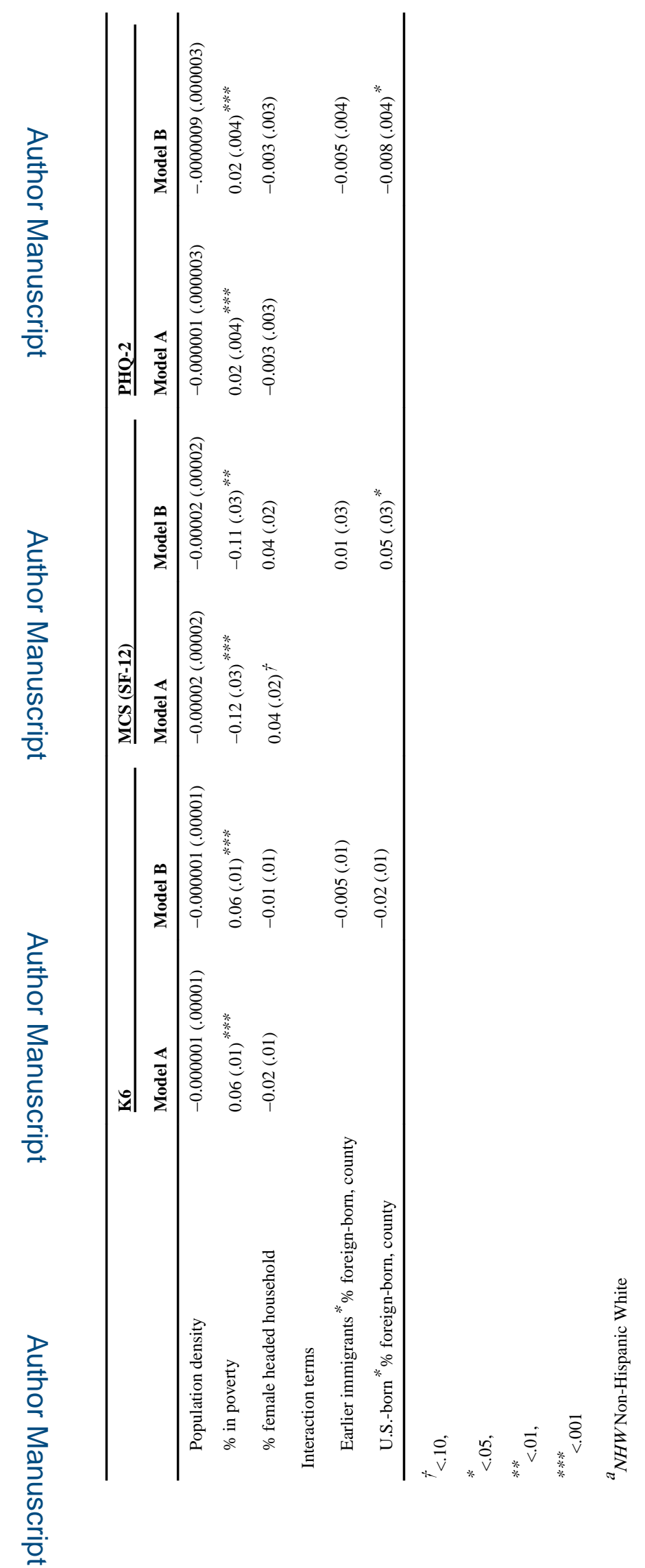

Psychiatr Q. Author manuscript; available in PMC 2016 December 01. 


\section{Table 4}

Differential effects of county's foreign-born density (IV) on mental health status (DV) by immigrant status after controlling for all covariates in Table 3: $b$ (standard error [S.E.])

\begin{tabular}{llll}
\hline & \multicolumn{4}{l}{$\mathbf{b}$ (S.E.) for \% foreign-born, county } \\
\cline { 2 - 4 } Models run among & K6 & MCS (SF12) & PHQ-2 \\
\hline Recent immigrants & $0.04(.03)$ & $-0.08(.05)$ & $0.02(.01)$ \\
Earlier immigrants & $0.02(.01)$ & $-0.04(.02)$ & $0.01(.004)$ \\
U.S.-born & $0.01(.007)$ & $-0.02(.02)$ & $0.002(.002)$ \\
\hline
\end{tabular}

